\title{
Conservation genetics of amphibians
}

\author{
TJC Beebee \\ Biochemistry Department, School of Life Sciences, University of Sussex, Falmer, Brighton BN1 9QG, UK
}

\begin{abstract}
Amphibians are good models for investigating the genetics of wild animal populations because they are: (1) widely distributed in most ecosystems; (2) easy to sample in breeding assemblages; (3) often philopatric to breeding sites, generating high levels of population genetic structure; (4) amenable to controlled crossings in the laboratory; and (5) of major conservation concern. Neutral genetic markers, mostly microsatellites, have been used successfully in studies of amphibian effective population sizes and struc-
\end{abstract}

tures, and in assessing the consequences of hybridisation. Phylogeography has provided important insights into population histories and the fates of introductions. Quantitative genetic methods have demonstrated adaptive variation in life history traits of importance to fitness and therefore to population viability.

Heredity (2005) 95, 423-427. doi:10.1038/sj.hdy.6800736; published online 17 August 2005

Keywords: amphibian; conservation; population genetics; phylogeography; adaptive variation

\section{Introduction}

Amphibians are found on all continents except Antarctica, and more than 5700 species are recognised. They are attractive subjects for population genetics for several reasons. Most have limited mobility, thus predisposing population structure over relatively short distances, and many are easy to sample because they congregate at specific localities (ponds) for reproduction (Beebee, 1996). Fertilisation in anurans (frogs and toads) is external, and controlled crosses are often possible under laboratory conditions. Unfortunately, amphibians are also undergoing major global declines and in recent decades have become more threatened than birds or mammals (Stuart et al, 2004). This highlights a special need for the application of conservation genetics to amphibian populations, and many suitable molecular markers have been developed (Jehle and Arntzen, 2002). Space in this short review does not permit comprehensive referencing, and instead I have therefore attempted to summarise with examples some major findings of recent studies. Inevitably, this means that many equally interesting papers have not been cited.

\section{Population size and diversity}

It is widely recognised that determining the genetic effective population size $\left(N_{\mathrm{e}}\right)$ is more important than measuring census size $\left(N_{c}\right)$ in wild populations because $N_{\mathrm{e}}$, usually a lot smaller than $N_{\mathrm{c}}$, is a much better indicator of long-term viability. Indeed, $N_{\mathrm{e}}$ is the parameter of primary interest to population geneticists. Unfortunately, demographic estimates of $N_{\mathrm{e}}$ are usually difficult, but comparison of allele frequency changes between generations permits estimation of $N_{\mathrm{e}}$ by genetic

Correspondence: TJC Beebee, Biochemistry Department, School of Life Sciences, University of Sussex, Falmer, Brighton BN1 9QG, UK.

E-mail: t.j.c.beebee@sussex.ac.uk

Received 9 June 2005; accepted 21 July 2005; published online 17 August 2005 methods. In general, amphibian breeding assemblages at ponds commonly have $N_{\mathrm{e}}<100$ (Beebee and Griffiths, 2005). Theory suggests that such small populations are susceptible to genetic depletion through drift and inbreeding, with adverse consequences for viability. Other genetic methods based on measuring a transient excess of heterozygosity relative to allele numbers, or ratios between numbers of microsatellite alleles and distances between allele sizes, can also be used to assess whether recent bottlenecks account for these small population sizes. Heterozygosity excess, for example, is a predicted consequence of the more rapid loss of rare alleles than of overall heterozygosity during a rapid population decline. In theory, it can demonstrate bottlenecks over a period of $0.2-4.0 \times N_{\mathrm{e}}$ generations, which for an amphibian population of $N_{\mathrm{e}}=100$ translates into approximately 70-1400 years before the present. The usefulness of these methods has, however, proved variable. Dramatic declines ( $>80 \%$ over the past $30-40$ years) of the Australian bell frog Litoria aurea generated no bottleneck signatures when 21 populations were assessed with four microsatellite loci (Burns et al, 2004). By contrast, data from 12 microsatellite loci provided evidence of recent bottlenecks in eight populations of European tree frogs Hyla arborea in Denmark, where the species has declined rapidly in recent decades. Moreover, these populations showed low fitness (larval survival correlated inversely with inbreeding coefficients) and genetic diversity was positively correlated with population size (Andersen et al, 2004). Similar consequences of high genetic load have been detected in a small and isolated natterjack toad Bufo calamita population in Britain (Rowe and Beebee, 2003), and this problem seems set to increase as habitat fragmentation continues apace.

The availability of museum specimens has permitted some interesting studies of population size based on comparisons of microsatellite genotypes in historic and extant population samples. The leopard frog Rana pipiens is widespread in North America, and though still abundant in the east, it has declined recently in the Pacific northwest. Eastern populations have maintained 
high genetic diversity (microsatellite heterozygosities $>0.86$ ) and effective population sizes between a few hundred and less than 2000, although these estimates depended somewhat on the precise analytical method used to compare allele frequency changes over time (Hoffman et al, 2004). Taken together, the data suggested that these frog populations were relatively stable, rather than comprising dynamic metapopulations with extinctions and recolonisations. Currently isolated, peripheral populations in the northwest had much lower genetic diversity than those further east, but historic samples suggested this had always been the case (Hoffman and Blouin, 2004). This result suggests a cautious approach to the increasingly popular idea of genetic rescue, the adding of genetically diverse stock to invigorate small isolated populations, since isolated range-margin populations with local adaptations may be of evolutionary significance. In any case, large-scale patterns of genetic diversity may not reflect differences between rangemargin and range centre populations based solely on increased drift and restricted gene flow at the range edge. In the Italian agile frog $R$. latastei postglacial recolonisation from an easterly refugium probably explains the current gradient of diversity at microsatellite loci, in which peripheral populations in the east still have relatively high heterozygosities (Garner et al, 2004). History is clearly an important factor in determining patterns of genetic diversity in amphibians as well as in many other taxa.

\section{Population structure}

For the European tree frog, a breeding assemblage approximated to a discrete population and there was little gene flow between ponds (Andersen et al, 2004). The pattern of population structure, however, varies substantially even among apparently similar species. The frog $R$. temporaria and the toad B. bufo are widespread and syntopic in Britain, and often share the same breeding sites. However, whereas toads formed discrete populations associated strongly with individual ponds, with high intersite $F_{\text {st }}$ estimates, gene flow among frog ponds was much higher over the same geographical distances, to the extent that it made little sense to define a pond aggregation as a discrete population for $R$. temporaria (Brede and Beebee, 2004). Genetic analysis of amphibians has therefore highlighted a general problem in ecology, the functional definition of a population. However, genetic methods also offer a solution. Maximum likelihood and Bayesian approaches underpin assignment methods based on genotypic disequilibria that do not depend on genetic equilibrium in the way that classical F-statistics do. Assignment methods allow populations to be defined from genotype clusters without any preconceptions based on the sampling sites. They also permit the detection of current migrants in populations, whereas F-statistics give only an average rate of gene flow over historical time, assuming equilibrium conditions apply. Andersen et al (2004) employed assignment methods to define their tree frog populations. Application of assignment tests using genotype data from multiple ponds to a newt Triturus cristatus metapopulation in France demonstrated asymmetric migration patterns between ponds, while simultaneously estimating $N_{\mathrm{e}}$ at each pond (Jehle et al, 2005).
Such methods have great power to quantify fine-scale population processes and are likely to become increasingly sophisticated and valuable in conservation genetics.

The relatively low mobility of amphibians makes them ideal for studying barriers to dispersal, both ancient and modern. Microsatellite analysis of Columbia spotted frogs $R$. luteiventris in the western USA demonstrated, using partial Mantel tests, that mountain ridges between valleys effectively limit migration (Funk et al, 2005). A combination of exact tests and Bayesian clustering methods also permitted upper and lower estimates for the number of genetically distinct populations occupying the 28 study ponds. Recent, anthropogenic changes in habitat structure can also be detected. A mixture of microsatellite and AFLP markers was employed to investigate how the stream-breeding salamander $D i$ camptodon tenebrosus has responded to forest clearances in British Columbia (Curtis and Taylor, 2004). This species occurs at greatly reduced population densities after clear-felling, and the study showed that this was associated with a much lower genetic diversity than is found in native woodland. It was estimated in this case that the genetic diversity of salamanders in cleared areas would take at least 200 years to recover, assuming regrowth of the forest permitted population recovery. Agricultural intensification has posed serious threats to amphibians, one of which is the fragmentation of natural habitats and increased population isolation. Studies of toads $(B, b u f o)$ in English farmland showed that population size and genetic diversity (assessed at three minisatellite loci) were correlated with pond density and land use, highlighting critical components such as woodland, hedgerows and sheep pasture in the connectivity of these populations (Scribner et al, 2001). Spatial autocorrelation of allele frequencies permitted estimation of 'patch size', in this case interpond intervals of $\leq 2 \mathrm{~km}$, associated with significant gene flow and thus the spatial scale at which landscape features become important.

Finally, it is also possible to address the intriguing question of sex-specific differences in dispersal rates using microsatellite data. 'Instantaneous' (single-generation) comparisons of F-statistics between the two sexes, and assignment tests, indicated the occurrence of femalebiased dispersal in bullfrogs $R$. catesbeiana (Austin et al, 2003) and subsequent studies have found sex biases, usually minor, in several other species. Such information will be very useful in understanding both reproductive behaviour and colonisation patterns.

\section{Hybridisation}

Hybridisation following admixture of species that are normally allopatric can lead to homogenisation of the parental genotypes, or to the decline of one or other of them. This threat to biodiversity can arise after anthropogenic translocation of one species outside its natural range. There are examples of this problem among the amphibia, including the hybridogenetic frogs $R$. lessonae and $R$. ridibunda in Europe. Hybridogenesis is a very unusual form of reproduction in which a hybrid (' $R$. esculenta') persists and spreads in populations with just one or other parent, usually $R$. lessonae, with which it backcrosses over multiple generations. This is possible 
because one of the parental genomes (usually lessonae) is destroyed in germ cells prior to meiosis (for a summary see Beebee, 1996). The initial crosses (lessonae $\times$ ridibunda) are relatively rare, with the result that esculenta have a restricted subset of the available ridibunda genotypes, often only one in any particular population. Because the ridibunda genome essentially becomes clonal in the hybrids, it is expected to accumulate deleterious mutations over time. Recent studies have confirmed this prediction. Crossing esculenta individuals bearing different ridibunda clones, derived from different initial hybridisations, yielded viable progeny whereas crosses bearing the same clone (as commonly occur together in natural populations) were nonviable (Guex et al, 2002). Introduced $R$. ridibunda have replaced $R$. lessonae in several areas of western Europe in recent decades, probably because hybridisation favours increasing numbers of $R$. ridibunda in situations where the incoming ridibunda genomes are novel, and thus still viable in interhybrid matings (Vorburger and Reyer, 2003). The hybrids are then able to overwhelm $R$. lessonae in shared habitats. This is exactly what has happened in places where $R$. ridibunda has been introduced.

The source of potentially damaging introductions, when undocumented, can also be investigated using molecular markers. Sometimes this can give important clues about the future potential invasiveness of the species in question. Analysis of 40 allozyme loci strongly suggested that the origins of introduced Italian crested newts T. carnifex in Switzerland, where the congener $T$. cristatus is native, were probably in the Tuscany region (Arntzen, 2001). These two species of newt hybridise freely, and the F1 offspring have high viability but low fertility, thus potentially compromising populations of the native species.

\section{Phylogeography}

Phylogeographic analysis, mostly using mitochondrial (mt) DNA, has been very successful in elucidating the history of wildlife populations. The uniparental inheritance and (virtual) lack of recombination in mtDNA makes it highly suitable for tracking genealogies through time. With amphibians mtDNA studies have indicated probable sites of glacial refugia, likely postglacial migration routes, and evidence of other vicariance events including some of unknown character. Cytochrome $b$ sequence comparisons in the red-legged frog $R$. aurora, for example, confirmed the distinctiveness of two lineages separated by a phylogeographic boundary of uncertain origin shared by several other taxa in northern California (Shaffer et al, 2004). This study also highlighted the populations most appropriate, on the basis of genetic similarity, for future reintroductions planned for an area of California. However, studies on another montane frog ( $R$. cascadae) in the same region of western North America highlighted the difficulties of using molecular data to define distinct population segments (DPS) for conservation management (Monsen and Blouin, 2003). In this case, mtDNA sequences indicated the existence of three distinct DPS whereas microsatellites suggested just two. Possible explanations for the discrepancies between the inferences from these markers include sex-biased gene flow and the higher probability of mitochondrial haplotype fixation, compared with fixation of microsatellite alleles, in small populations due to the four-fold lower $N_{\mathrm{e}}$ of mtDNA compared with nuclear loci.

The population dynamics of species introductions can also be investigated retrospectively using polymorphic genetic markers. In this context the complex introduction history of cane toads $B$. marinus on tropical islands in the Pacific and Caribbean regions was investigated using a Bayesian model with data from microsatellite and allozyme markers, coupled with extensive nongenetic information (Estoup et al, 2001). Evidence of early admixture from multiple releases, initial bottlenecks, population expansions and later stabilisations was sought and often found by the genetic analysis. This paper provides a valuable comparison of information obtained with different marker types in populations not yet at equilibrium.

By contrast, it is sometimes not clear whether a population near a range margin is native or the consequence of a human translocation. This is particularly problematic when a suspect population is separated from others by a major barrier to movement, such as seawater. Phylogeographic analysis using microsatellites and RAPD markers has been used to investigate a case of this type in Britain, notably the status of the pool frog $R$. lessonae. Two independent studies concluded that this frog, previously a presumed introduction, was actually a long-standing native at its range edge (Zeisset and Beebee, 2001; Snell et al, 2005). The distinction is important because it can make the difference between extirpation as an undesirable alien or conservation as an endangered species.

\section{Adaptive variation in amphibians}

Anuran amphibians have features that make them useful subjects for investigating adaptive variation using the standard techniques of quantitative genetics. Explosive breeding cycles, external fertilisation and high fecundity make controlled crosses relatively easy. Furthermore, growth and development rates, and survival, during embryogenesis and the larval phase as well as size at metamorphosis are all well established and conveniently measured life history fitness traits (Beebee, 1996). The European common frog $R$. temporaria has been the subject of many studies of adaptive variation, particularly by comparing populations at different latitudes and thus likely to be adapted to very different environmental conditions. All the above fitness traits proved heritable in this species, and both additive and nonadditive genetic variances were significant in all or most of them (Laurila et al, 2002). By contrast, this study also showed that plasticity in larval growth rates (the ability to develop faster when pond desiccation threatens) differed between populations at high and low latitudes but showed no genetic variation within populations. The low-latitude frog population had a higher desiccation risk that in the north, primarily due to the warmer climate, and response plasticity was present in the south but not the north. Genetic variation in plasticity within populations has however been detected in other anurans.

Maternal effects, mostly related to variations in egg size, were also significant in the cases of larval growth rates and sizes of $R$. temporaria metamorphs (Laugen et al, 2002). Egg size variation was probably mediated mainly 
by environmental effects on female size, although there may also have been genetic components to this variable. In general, though, the largest females produced the largest eggs (presumably a consequence of living in resource-rich habitats) and these were positively correlated with subsequent fitness traits. Surprisingly, in laboratory experiments the heritability of larval growth rates was highest at optimal growth temperatures rather than at (presumably) more stressful suboptimal ones, and environmental variance was a stronger determinant of variation in heritability of this trait than additive genetic variance (Uller et al, 2002). However, in general, the heritabilities of these traits have proved rather low, as expected for attributes strongly correlated with fitness. Furthermore, different stresses do not always have the same consequences. Anthropogenic acidification of breeding ponds has posed a threat to many amphibians, because the viability of embryos of many species declines sharply at low $\mathrm{pH}$. However, $\mathrm{pH}$-induced stress did not significantly alter the heritabilities of critical viability factors (survivorship, deformity, body size and shape) in $R$. temporaria larvae, implying that acidification is unlikely to compromise the adaptive potential of these frogs in the polluted environment (Pakkasmaa et al, 2003). This study also found approximately equal contributions of additive and dominance genetic components, and a strong influence of maternal effects, on variation in all the studied traits.

Another interesting question relates to the superimposition of fine-scale (local) environmental variation on large-scale selection pressures. Comparisons of multiple frog populations from a range of different latitudes in Sweden demonstrated countergradient variation in larval development rates, which in the laboratory increased as a function of latitude as expected (where the available growth period is shorter) but which in the field were not latitudinally ordered (Laugen et al, 2003). Evidently local environmental effects were able to override clinal genetic variation in this trait. This leads to a related question about how genetic variety is compartmentalised among populations at various levels of geographic scale. Comparisons of genetic differentiation among common frog populations at neutral (microsatellite) loci, as estimated by $\mathrm{F}_{\mathrm{st}}$, and in the life history traits described above as estimated by $Q_{\text {st }}$, has shown that the latter are more strongly differentiated than the former, while both exhibit isolation-by-distance effects (Palo et al, 2003). These investigations have important implications for conservation managers considering the translocation of amphibians, and strongly imply that selection is acting on these quantitative traits that are of high significance for fitness.

\section{Future directions}

Not all amphibians are equally amenable to population genetic studies. Urodeles (newts and salamanders) usually have internal fertilisation, lower fecundity than anurans, and produce larvae that are harder to rear in captivity than frog tadpoles. Many anurans, especially tropical species, do not assemble at ponds and produce few offspring. No doubt future work will focus mainly on the most tractable species, a selection of which is mentioned in this review. A more general limitation for genetic work with amphibians is their long generation time, which for most species is several years. Nevertheless, for many types of study this is not critical and there is great potential for more genetic research using wild populations of these widely available vertebrates. A major concern in conservation genetics is the extent to which variation at neutral loci, relatively easy to estimate, reflects adaptive variation that is more directly relevant to long-term population viability but which is more difficult to measure. Future work with amphibians could make a useful contribution to this debate because, as outlined above, some of these organisms are particularly amenable both to molecular and quantitative genetic investigations. Recent studies with common frogs $R$. temporaria indicate that such comparisons can indeed be very fruitful. Genetic diversity (at microsatellite loci) and larval fitness correlations were evident in this species, most strongly in stressful environments and best explained by the general (global genomic) rather than local (linkage) hypotheses (Lesbarrères et al, 2005).

Unfortunately the model amphibian most used in molecular biology (Xenopus laevis), and for which the most DNA sequence information is currently available, is of little value for population genetic work because it is tetraploid and because its ecology has been little studied in the wild. Genomic approaches involving the full sequencing of one or more anuran genomes from species useful in field studies are now highly desirable, and should eventually lead to the identification and characterisation of loci involved in the now well known fitness traits. This exciting prospect is certainly feasible in the near future.

\section{References}

Andersen LW, Fog K, Damgaard C (2004). Habitat fragmentation causes bottlenecks and inbreeding in the European tree frog (Hyla arborea). Proc Roy Soc London B 271: 1293-1302.

Arntzen JW (2001). Genetic variation in the Italian crested newt, Triturus carnifex, and the origin of a non-native population north of the Alps. Biodivers Conserv 10: 971-987.

Austin JD, Davilla JA, Lougheed SC, Boag PT (2003). Genetic evidence for female-biased dispersal in the bullfrog, Rana catesbeiana (Ranidae). Mol Ecol 12: 3165-3172.

Beebee TJC (1996). Ecology and Conservation of Amphibians. Chapman \& Hall: London.

Beebee TJC, Griffiths RA (2005). The amphibian decline crisis: a watershed for conservation biology? Biol Conserv 125: 271-285.

Brede EG, Beebee TJC (2004). Contrasting population structure in two sympatric anurans: implications for species conservation. Heredity 92: 110-117.

Burns EL, Eldridge MDB, Houlden BA (2004). Microsatellite variation and population structure in a declining Australian hylid Litoria aurea. Mol Ecol 13: 1745-1757.

Curtis JMR, Taylor EB (2004). The genetic structure of coastal giant salamanders (Dicamptodon tenebrosus) in a managed forest. Biol Conserv 115: 45-54.

Estoup A, Wilson IJ, Sullivan C, Cornuet JM, Moritz C (2001). Inferring population history from microsatellite and enzyme data in serially introduced cane toads, Bufo marinus. Genetics 159: 1671-1687.

Funk WC, Blouin MS, Corn PS, Maxell BA, Pilliod DS, Amish S et al (2005). Population structure of Columbia spotted frogs (Rana luteiventris) is strongly affected by the landscape. Mol Ecol 14: 483-496.

Garner TWJ, Pearman PB, Angelone S (2004). Genetic diversity across a vertebrate species' range: a test of the centralperipheral hypopthesis. Mol Ecol 13: 1047-1053. 
Guex G-D, Hotz H, Semlitsch RD (2002). Deleterious alleles and differential viability in progeny of natural hemiclonal frogs. Evolution 56: 1036-1044.

Hoffman EA, Blouin MS (2004). Historical data refute recent range contraction as a cause of low genetic diversity in isolated frog populations. Mol Ecol 13: 271-276.

Hoffman EA, Schueler FW, Blouin MS (2004). Effective population sizes and temporal stability of genetic structure in Rana pipiens, the northern leopard frog. Evolution 58: 2536-2545.

Jehle R, Arntzen JW (2002). Microsatellite markers in amphibian conservation genetics. Herpetol J 12: 1-9.

Jehle R, Wilson GA, Arntzen JW, Burke T (2005). Contemporary gene flow and the spatio-temporal genetic structure of subdivided newt populations (Triturus cristatus, T. marmoratus). J Evol Biol 18: 619-628.

Laugen AT, Laurila A, Merila J (2002). Maternal and genetic contributions to geographical variation in Rana temporaria larval life-history traits. Biol J Linn Soc 76: 61-70.

Laugen AT, Laurila A, Rasanen K, Merila J (2003). Latitudinal countergradient variation in the common frog (Rana temporaria) development rates - evidence for local adaptation. J Evol Biol 16: 996-1005.

Laurila A, Karttunen S, Merila J (2002). Adaptive phenotypic plasticity and genetics of larval life histories in two Rana temporaria populations. Evolution 56: 617-627.

Lesbarrères D, Primmer CR, Laurila A, Merila J (2005). Environmental and population dependency of genetic variability-fitness correlations in Rana temporaria. Mol Ecol 14: $311-323$

Monsen KJ, Blouin MS (2003). Genetic structures in a montane ranid frog: restricted gene flow and nuclear-mitochondrial discordance. Mol Ecol 12: 3275-3286.
Pakkasmaa S, Merila J, O'Hara RB (2003). Genetic and maternal effect influences on viability of common frog tadpoles under different environmental conditions. Heredity 91: 117-124.

Palo JU, O'Hara RB, Laugen AT, Laurila A, Primmer CR, Merila J (2003). Latitudinal divergence of common frog (Rana temporaria) life history traits by natural selection: evidence from a comparison of molecular and quantitative genetic data. Mol Ecol 12: 1963-1978.

Rowe G, Beebee TJC (2003). Population on the verge of a mutational meltdown? Fitness costs of genetic load for an amphibian in the wild. Evolution 57: 177-181.

Scribner KT, Arntzen JW, Cruddace N, Oldham RS, Burke T (2001). Environmental correlates of toad abundance and population genetic diversity. Biol Conserv 98: 201-210.

Shaffer HB, Fellers GM, Voss SR, Oliver JC, Pauly GB (2004). Species boundaries, phylogeography and conservation genetics of the red-legged frog (Rana aurora/draytonii) complex. Mol Ecol 13: 2667-2677.

Snell C, Tetteh J, Evans IH (2005). Phylogeography of the pool frog (Rana lessonae Camerano) in Europe: evidence for native status in Great Britain and for an unusual postglacial colonisation route. Biol J Linn Soc 85: 41-51.

Stuart SN, Chanson JS, Cox NA, Young BE, Rodrigues ASL, Fischmann DL et al. (2004). Status and trends of amphibian declines and extinctions worldwide. Science 306: 1783-1786.

Uller T, Olsson M, Stahlberg F (2002). Variation in heritability of tadpole growth: an experimental analysis. Heredity 88: 480-484.

Vorburger C, Reyer H-U (2003). A genetic mechanism of species replacement in European water frogs. Conserv Genet 4: 141-155.

Zeisset I, Beebee TJC (2001). Determination of biogeographical range: an application of molecular phylogeography to the European pool frog Rana lessonae. Proc Roy Soc London B 268 : 933-938. 